\title{
Staging Intersectionality
}

An Aesthetics of Action

\begin{abstract}
This essay follows the making of a queer of colour aesthetic space in the form of a music video entitled Brother, within a largely homogenous white University. The video places white heteronormativity on the periphery whilst intersectional brown bodies take the centre. It inverts racist and fetishistic tropes in music video culture and reverses the white male gaze. The making of the video created a small brown island in a sea of white as a vision of a future brown space protected from the ubiquitous, ambivalently festishizing white gaze; a gaze that projects its own narrative onto bodies of colour. It puts forward a thesis of racial agency, whereby the performance of "race" is scripted by the person of colour and not provoked by the construct of whiteness.
\end{abstract}

Keywords: intersectionality, music video, queer of colour, performance, disidentification

IT IS 2018 and I am an Associate Professor of Circus at Stockholm University of the Arts, and a recovering academic. Uncomfortably queer and brown within an overwhelmingly white institution, in a department governed by an invisible, unspoken cis-male heteronormativity, I find it my remit to work in, with and through art to interrogate what it feels like to try to orient one's hybridity in such a homogenous environment,

(C) The authors. Published by Föreningen Lambda Nordica under the CC BY-ND license. 
in order to feel at home. What would happen if I made brown queerness more visible and vocal on its own terms, rather than always just an echo effect of white heteronormativity?

Disorientation is a valued affect in art, especially in circus. Disorienting people in social situations, is not as prized. People can feel insecure if they cannot place you. But the opportunity of disorientating social identities is here. The time of needing to create unusual places to exist within is now. And it seems that this homogenous Swedish university is being called upon to accept disorientation and discomfort as its new default. If there was never one place for me to exist in, where I could bring all of my selves to the party and not leave one outside in the cold, it was because I never realized it was up to me to create one: a re-constituted narrative or aesthetic space to move and act within, or indeed an internal place of knowledge production within which to think. What kind of conditions would I need to create for a future home to be possible?

It would have to start in fantasy. I would need to make it up, because there is nothing at hand to use here except perhaps affects I am not interested in bringing with me into this new home. I would need to clear my own internal space first.

I see intersectionality as having to face more directions than some others have to face - those whose lives look like a straight line, a coherent plot, a continuous development that is easy to navigate. "Faggot" may come at me from the left, "nigga lips" from the right, "peasant" may be spat directly into my face while I am hit around the back of the head with "cissy". Each of these identities comes with different affects - shame, rage, fear, anxiety. And when more than one oppressive light turns green, you learn how to defend yourself on multiple fronts and cope with compound affects - shameful fear, anxious rage etc. Developing in the direction you want is difficult when you are constantly distracted. I will need to find homes for each of these affects to work themselves through before I can think about the future.

The film I will discuss here is entitled Brother. ${ }^{\mathrm{I}}$ Its premise is what would happen if I flipped the fantasy of white heteronormativity I am surrounded by. In this essay I will use the terms "colour" and "coloured", 
since I, with my South African heritage, would be defined as Cape Coloured - a term used to describe non-whites from the Cape sharing a plethora of mixed ancestral links, including indigenous Khoi, San and Xhosa people, European colonizers and slaves imported from the Dutch East Indies. The Swedish term rasifierad, or "racialised", for me (here), removes some agency in the power of naming one's own relationship to and performance of "race".

Taking the form of a music video, Brother placed white heteronormativity on the periphery while queer of colour took the centre. It inverted racist visual tropes and reversed the white male gaze by queering and colouring it. It created a small brown island in a vast sea of white, where we could develop our own language and do some re-writing of the script we had felt forced to perform in - a fantasy place for our rage to find a home in a Swedish institution blithely following a narrative in need of revision.

Brother responded to the white male, hetero cis need for a "cause" following \#metoo. If I and the coloured cast were tentative or nervous about this undertaking, the white filmmakers and cast were unafraid to take it to the extreme. And so, for two days, in a studio at the university, we implanted a temporary afro-revisionist and homo-aggressive aesthetic utopia.

We looked at how we, in a fantasy using contemporary visual and musical tropes, could re-imagine the injustices of colonialism, slavery and homophobia. We used circus, with all its apparatuses of ropes, shackles, pulleys and bindings, to show the white body as a powerless object of use, merely a prop in the black man's fantasy - a grime-style inspired rap telling the white man "you don't get to have a cause" - and set it within a shallow pool of water to represent the journey of bodies across water towards their social death.

Combining the identities of queer and black, with a strong textual affirmation of these forming an alliance with feminism, produced an uncanny, ambiguous performance in me, the central speaking figure. This is what I describe as staging intersectionality. 


\section{Scene One: A sea of white professors}

In 2013 we were assessing a project concerning blackness within a particular medium of performance making. No one looked to me to share my experiences on the matter. I had not been noticed as coloured and for the first time, it mattered to me.

As a teenager in British public school in 1984 , I wanted to pass as white, straight, and "well-bred". That play I enacted was performed for the purposes of physical and psychic survival. Rehearsing those movements and pronunciations so often that I could repeat them in my sleep meant they congealed into something natural.

It was therefore an innocent enough oversight, and my first lesson in the "innocence" of Swedish attitudes towards the complexities of race, when I was read for white.

So, I "came out" as having experienced the material at hand. Awkwardness, like a black bull in a china shop, entered the room. Fragile, white porcelain constructions were inadvertently broken. That was not my intention. There was, after all, an abstract universal governing the moment, something that could be described as objective, as neutral, which we would never admit is synonymous with white - like the white walls of a gallery that pretends it is empty until the art arrives. That white cube is always already crammed with colonial assumptions about the superiority of Western values. It is, in fact, anything but neutral. The universal is a fantasy.

Where their knowledge was housed, where they were at home with their expertise, was called into question. Uncanny, no longer familiar I had disoriented them: they were momentarily lost at sea.

Faced with the comedy of white awkwardness, should I step back into the closet, go back below deck and put my brownness back into brackets?

Or should I make race matter, lest it be made for me? This is what racial agency may look like: race as a clay rather than set in stone by a white craftsman, sewing stones in my gut or stuffing them in my pockets; race as a material of emancipatory poetics, not a material that binds me in place and makes me sink.

I find a companion here in choreographer Miguel Gutierrez's Does Abstraction belong to White People? 
What are my materials for this current crisis of identity? How did I come to be colonized? And how did I find out that I had been colonized? Have I found out? How did I come to equate family and origin as violent and threatening? How did whiteness become, I shudder even to write this, safety - a lack of feeling, a lack of allegiances. It made space, or at least I thought it did, for me. For a me that had no history. (Gutierrez 2018)

Since then, whiteness has become the direction I most want to face - a whiteness not to be conflated, at least not in every instance, with white people. I want to face it because I want to see it, this director calling the shots, invisible but for its voice, coming from the darkness of the stalls with an interpretation of the script we are all reading from, some more consciously than others.

Some of us are sight-reading: our life's training has demanded we learn that particular skill, to pass as literate in a scene not written with us in mind. Others know the script by heart, since it was written for them to excel in: for them it seems natural. And some of us, having not only learned it, but studied and analyzed it, have "actioned" it: an acting technique wherein the actor adds transitive verbs to every phrase they utter. "Actioning" the script means taking conscious decisions about how to say our lines, about what our lines are acting upon in a certain time and space, so that emphasis and rhythm deliver a word we all know but in a way that denaturalizes it, making it uncanny because perhaps we bring a different history to the word that illuminates geographies previously foreign to everyone else at the table. Doing this means being in several places at the same time and, unlike the experience of the white professors, it is most certainly not about feeling at home.

\section{Scene Two: An island of queer colour}

Four racially and sexually ambiguous men lounge on a tropical island surrounded by water. In the water, marble white, athletic male bodies in underpants lie passive, displaying their goods. They are dragged violently to the steps of the island, to the feet of the central figure, the "mother" of this creole house, who expresses his disdain: 


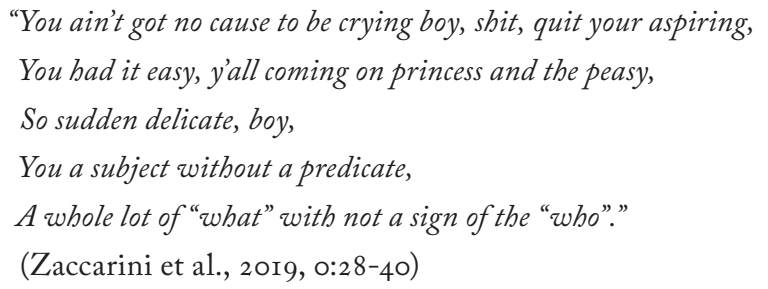

Something happened on that island between takes. "Represented" on that platform were mongrel mixtures of Haiti/Sweden, South Africa/ Italy, Columbia/Sweden, Kenya/France - a colourfully swaggy Afropean vision painted in multi-hued tar brush strokes under the hot lights - and near naked in the cold water, the genealogically pure and homogenously hued thoroughbreds from Sweden and Holland. It was a shift in style, an ebonic play, a gestural and sonic language that arises when white people are not around - when people of colour share their experience with each other in a safe space, or in this case a space protected by water. I circulate in Swedish institutions of culture and education where whiteness, and often straightness, are a default; these spaces are not designed for me, I am constantly bumping into the furniture. For the first time I realised how therapeutic and nourishing it was to be on a coloured island surrounded by water where whiteness was kept at a distance. It gave me a sense of relief I had not known I needed: a demarcation of territory, the cutting up of land, a Pan-African moment, an afro-revisionist fantasy. We warm on the island, the "boys" shivering in the water.

Since that moment on our island surrounded by water, I sought out more moments in between takes, where I could laugh freely, cry without invoking white guilt and find support in the ongoing struggle with micro-racism via a solidarity in histories and genealogies that were not even my own: Haiti, Columbia, Kenya, South Africa. Our stories, temporalities and geographies did not come together on that fantasy island in any sort of linear sense, but within what might be called a future fantasy of epiphenomenalism. Michelle M. Wright, who re-works the concept of the epiphenomenal for Black Studies in The Physics of Blackness, describes it in the following way: 
Our constructs of Blackness are largely historical and more specifically based on a notion of space-time that is commonly fitted into a linear progress narrative, while our phenomenological manifestations of Blackness happen in what I term Epiphenomenal time, or the "now," through which the past, present, and future are always interpreted... Read together, they underscore the depth and breadth with which these notions of space-time pervade Western expressions of collective identity, most especially Blackness....they underscore that while the linear progress narrative is an invaluable tool for locating Blackness, when used alone its very spatiotemporal properties preclude a wholly inclusive definition of Blackness, yielding one that is necessarily inaccurate.

(Wright 2015, 4)

The "phenomenological manifestations" of my brownness are scenes that happen in a specific time and place. Tracing them back over my last seven years in Sweden, these happenings are nearly always provoked into being by white people. And they have been calling the shots as to how the racialized narrative should play out.

In this curated racial bricolage, our collective brownness fortified us against the racist, xenophobic gaze that was meeting us in Stockholm's streets at a moment when the Sweden Democrats (who are a nationalist and right-wing populist political party in Sweden) were celebrating their gains and coming out into the open. I hoped the screenings would do the same for other brown folk - that they would contribute to racial uplift and agency.

The island is what I call an aesthetic prototype: I encounter microracism on the street, at school, at a dinner party. Unsure as to whether a comment or action is indeed racist, I am unable to act. I grew up in London, where racism is direct, and my mother is from the Cape Townships, where structural racism was policy rather than implicit or disavowed. The trope around how people of colour respond to this, is that they take this uncertainty home with them and itch with self-doubt. I decided to use these micro-racist encounters as material to take into the studio rather than home, and work with them. I invent witty comebacks, char- 
acters, small pedagogic performances in which whiteness is schooled in its unconscious racism. When the shelves of my archive of micro-racism are stuffed, I create aesthetic objects such as this film. It is a prototype, in the aesthetic realm, of a brown space protected from the ubiquitous, ambivalently fetishizing white gaze projecting its storyline onto us: Was that look "get out of my country"? Or was it "get into my panties"?

This film is how we begin to take action - with the aesthetics of epiphenomenal bodily story-lines - showing just how staged the conversation around race and otherness has been within the university. We re-staged it and gave it a brown director so others could witness an alternative representation of coloured and queer agency in the Nordic context. We made the narrative a little more complicated.

This complication is a pile-up at the intersection, and the things I collect and bring into the music video are the body parts that lay scattered on the tarmac - a whole body, dismembered by the collision caused by opening the intersection to all the traffic that has been put on hold to get me through my day: my whiteness, my blackness, my maleness, my queerness, broken up into components. This is a forcing of the body to remember what has had to be foreclosed in order for it to function as a one-way narrative - a one-story body that has tried to make sense, tried to be legible within the dominant script but which could only ever achieve this as disabled, cut off from its full potential: a part-object, bit part or fetish. This is the body that needs to fall apart a little, if it is to find a new, more active and enabled way to move through the world.

Once a critical awareness of intersectionality re-members the body's potentialities and uncovers its divergent histories, it might see itself as always having been in bits and pieces, unable to cohere, and therefore take action. This awareness could be the beginning of the work to (re) construct a bodily aesthetic capable of expressing all those lines, voices, movements of history and movements of thought in a whole body that refuses easy classification in a system of political, juridical, social or cultural power. This is an aesthetic practice, and in the light of Swedish elections, a social performance with political intent. 
This is where aesthetics, outside of the studio, turn into actions; where, walking down the street I have Malcolm X and RuPaul and Angela Davis and Beyoncé in my unapologetic strut.

Whiteness, whatever you are, you are not real. I do not need you anymore to define myself. On this catwalk, it will be I who will define the category of "realness".

\section{Scene Three: White bodies}

The still, disinterested gaze of the coloured agents on the fantasy island is directed at the white bodies being dragged across the water, by feet, wrist or neck, to the auction block. The frame is filled with body parts - buttocks, baunches, groins, abdominals, blond hair - but not faces. Only the queer coloureds have faces whose gaze fetishizes, not complete subjects, fit for social life or properly buman relations, but part-objects to be used or traded. One of the white bodies is drawn up into the air by the ropes, and hangs lifeless above them, like a trophy they have already forgotten about.

This still, uncompromising coloured gaze reminds me of how Toni Morrison in The Bluest Eye, described the eyes of white folk looking at coloureds: a "vacuum where curiosity ought to lodge...the total absence of human recognition...the vacuum edged with distaste..." (Morrison 20I7, 43). She describes how:

I destroyed white baby dolls...But the dismembering of dolls was not the true horror. The truly horrifying thing was the transference of the same impulses to little white girls. The indifference with which I would have axed them was shaken only by my desire to do so.... To discover what eluded me: the secret of the magic they weaved on others...If I pinched them, their eyes - unlike the crazed glint of the baby doll's eyes - would fold in pain...When I learned how repulsive this disinterested violence was...my shame floundered about for refuge. The best hiding place was love. Thus, the conversion from pristine sadism to fabricated hatred, to fraudulent love. (Ibid., 38) 
Identification at its most basic is to want to be like. Verisimilitude. Likeness. To be like, liked, likened to something - to be recognized. Vanillitude. On the one hand, desire to be like is based on the image, but that image is only beautiful because of the symbolic place it holds in culture, in politics, in power.

Morrison describes the fascination with the "magic" of whiteness that eludes the character of The Bluest Eye; it makes whiteness attractive. This "magic" is the power that whiteness has accrued through violence and sadistic domination. And it is "magic" because it is mystifying: a trick.

If I follow the path of sadism to hatred to desire that Morrison maps out, I can see how the hegemonic beauty ideals of whiteness have been yet another device in racism's epistemological bag of tricks. This is why aesthetics, both imaginary and symbolic, can also be a powerful tool in anti-racist struggles.

If I cannot have you (desire), then I will try to be you (identification). Conversely, if I cannot be you, then perhaps at least I can try to have you. If neither works out, I may just have to erase (dismember) you (sadism).

\section{Scene Four: A (David) Lynch Diva}

The mother of the island stands alone in a gold-sequined dress, her afro slicked back. She could be about to sing a song in a I940's nightclub. Her gaze suggests that she knows she has gotten away with something and she does not mind the fact that you disapprove. She does not need your recognition. As the camera retreats, we see why she has this glint in her eye. The white bodies come into view, now hanging by their feet, slowly spinning around her, stroking themselves in rapture - a carousel of white meat hanging in the light. This is the sadism Morrison mentions: white human men as white inhuman dolls - objects of experimentation.

The glint in the eye of the cross-dressed, cross-identifying mother figure indicates, for me, that she knows she is in the middle of a scene that should not really be allowed to happen. Least of all in a white university. "Yessa Massa, I can't help it, sorry Massa, I didn't know the rules. Was that not allowed?" 
Lynching was the unconsciously sexual expression of racism in the Reconstruction. The coloured, cross-dressing queer mother (of the House of Immaculate Reparation?), overwritten with numerous and contradictory sexual inscriptions, brings forth a black imaginary of historical revisionism. The nearly-white, not quite drag figure is yet another inversion, for it was often the white woman that set into motion the sexual insecurity and jealousy of the white man to dismember and hang the black man's body to see if he could finally rob it of the threat it posed to his potency.

But this is a different fantasy: the white bodies are still in a form of rapture, still caught up in desire - because they can afford to. Racism has never been a systemic reality for them, so it is perfectly possible to use it as a fantasy scenario. History has afforded them this - to take a vacation from privilege - to have a holiday romance with revisionist racism.

In the process of finding solidarity in theory and literature, I discover Michele Wallace's interpretation of a passage in Eldridge Cleaver's Soul on Ice, where he puts forward a theory of the black male homosexual. Cleaver describes how, in taking the white man as his lover, the black man is deprived of his masculinity, in that his love of whiteness castrates his black power (Wallace 2015, 67).

This passage is significant for how Wallace takes issue with the hetero-machismo of the Black Power movement - in her view the very thing that prevented African American women from joining the movement as feminists rather than secretaries or food providers and thereby dooming the project to failure. For Cleaver, the black homosexual is counter-revolutionary, reduced to the place of black women who were fucked/raped by white men. However, Wallace points out that if it were the black man doing the fucking, he would be just as much, if not more of a revolutionary than the black heterosexual (Ibid., 68).

With her speculations in mind, the crisscrossed identifications of queer coloured machismo within the film become clear. The camera is a vivisecting queer coloured male gaze upon the white male body, an inversion of the heterosexual hip-hop gaze upon the woman's body 
that cuts it up into object body parts. The revolutionaries here are the queer macho coloureds vivisecting the white male body, cutting it up into body parts, appropriating the pornographic power of this disinterested white gaze. It is an inversion, a spectacular, sadistic failure - as all sadistic ventures are. Driven by revenge, the coloured male figures on the island become the masochistic white male's object of desire. And although it failed to produce any proposals for a kinder future, it succeeded in confronting its viewers with an alternative representation of these beautiful icons of white success, thus creating space for an even more awkward dialogue. Failure is a procedural necessity; it is a necessary clearing of deleterious affects that prevent a real sense of agency and future thinking.

The brown agent at the crossroads between black and white, the queer macho in a dialectical and disidentificatory dynamic with gender, become possible figures for imagining, imaging and staging spaces that point to a future, intersectional brownness or queerness beyond the binary.

john-Paul zaccarini, PhD, is Professor of Performing Arts for Bodily and Vocal Practices at the Research Centre UNIARTS. The short film Brother is a part of his performance lecture The MixRace MixTape performed at Södra Teatern in Stockholm March 2020 (available on Youtube) and is a track on the album of the same name (available on Spotify). His current research, FutureBlackSpace, creates safe, generative spaces of recovery and discovery for black and brown artists to explore their work without the presence of the white gaze.

\section{REFERENCES}

\section{FILMOGRAPHY}

Brother. 20I9. Directed by John-Paul Zaccarini, Erwin Semler and Joachim Karlsson. https://www.youtube.com/watch?v=fpRjDSJjd 2 I 


\section{BIBLIOGRAPHY}

Gutierrez, Miguel. 2018. "Does abstraction belong to white people?” BOMB Magazine, November 7, 2018. https://bombmagazine.org/articles/miguel-gutierrez-I/

Morrison, Toni. 2017. “The Bluest Eye.” In Race. London: Vintage.

Wallace, Michelle. 20I5. Black Macho and the myth of the Superwoman. London/ Brooklyn: Verso.

Wright, Michelle M. 2015. Physics of Blackness: Beyond the Middle Passage Epistemology. Minneapolis: University of Minnesota Press.

\section{NOTES}

I. Brother. 20I9. Directed by John-Paul Zaccarini, Erwin Semler and Joachim Karlsson. https://www.youtube.com/watch?v=fpRjDSJjd $2 \mathrm{I}$ 